DOI 10.37882/2500-3682.2020.05.18

\title{
ПОНИМАНИЕ КАК КОМПОНЕНТ ПОЗНАВАТЕЛЬНОЙ ДЕЯТЕЛЬНОСТИ И КУЛЬТУРНОЙ КОММУНИКАЦИИ
}

\section{UNDERSTANDING AS A COMPONENT OF COGNITIVE ACTIVITY AND CULTURAL COMMUNICATION}

G. Trofimova

M. Terekhina

Summary: This article deals with the problem of understanding in scientific research and cultural dialogue. It is noted that the main factors that initiated the analysis of the problem were the facts of «incommensurability» of theoretical concepts in natural Sciences and Humanities. The problem of incommensurability in humanitarian knowledge also exists and is particularly relevant in connection with the expansion of the field of dialogue between cultures. Culture, as is known, is a special type of information process, a superbiological form of accumulation, storage and transmission of information. Cultural values, norms and patterns can become objectified only with the help of non-genetic sign systems, cultural texts. Language elements taken by themselves, without relation to the person and culture, have no sense. To understand the peculiarities of language aspects, it is necessary to study the culture in the field of which the language was formed. Language sign systems act as carriers of meanings. The authors come to the conclusion that understanding is the result of conceptual and linguistic communication, which needs logical understanding and rational control.

Keywords: understanding, meaning, meaning of language, idea of incommensurability, language communication.
Трофимова Галина Петровна

К.культурологии, доцент, Орский гуманитарно-технологический институт (филиал) ОГУ trofimova18.60@mail.ru

Терехина Майя Ивановна

К.фр.н., доцент, Орский гуманитарно-технологический институт (филиал) ОГУ m.teriohina@mail.ru

Аннотация: В данной статье рассматривается проблема понимания в научном исследовании и культурном диалоге. Отмечается, что основными факторами, инициировавших анализ проблемы, стали факты «несоизмеримости» теоретических понятий в естествознании и в гуманитарных науках. Проблема несоизмеримости в гуманитарном знании также существует и особенно актуализируется в связи с расширением поля диалога между культурами. Культура, как известно, выступает особым типом информационного процесса, надбиологической формой накопления, хранения и передачи информации. Культурные ценности, нормы и образцы могут стать объективированными только с помощью внегенетических знаковых систем, культурных текстов. Языковые элементы, взятые сами по себе, без отношения к человеку и культуре, никакого смысла не имеют. Чтобы понять особенности языковых аспектов, нужно изучать культуру, в поле которой язык формировался. Языковые знаковые системы выступают как носители смыслов. Авторы приходят к выводу о том, что понимание является результатом понятийно-языковой коммуникации, которое нуждается в логическом осмыслении и рациональном контроле.

Ключевые слова: понимание, значение, смысл языка, идея несоизмеримости, языковая коммуникация.
$\mathrm{B}$ ажнейшей основой существования и жизнедеятельности социума и культуры является коммуникация в разнообразных способах и разновидностях. Одним из наиболее распространенных вербальных и невербальных способов выступает языковая коммуникация, целью которой является непосредственная передача и хранение информации, обмен ею и, в конечном счете, взаимопонимание людей. Возможность взаимопонимания обусловлена идентичностью психофизиологической организации людей, онтологическим единством многообразного мира и социальной общностью людей на основе общественно-исторической практики, которую обеспечивает язык.

Поэтому по-прежнему не теряет своей остроты проблема понимания. Решить данный вопрос пытались многие философские направления, в том числе и герменевтика [9].

В гуманитарном знании проблема актуализируется в связи с расширением поля диалога между культурами. Культура, как известно, выступает особым типом информационного процесса, надбиологической формой накопления, хранения и передачи информации. Культурные ценности, нормы и образцы могут стать объективированными только с помощью внегенетических знаковых систем, культурных текстов. При этом, сами знаковые системы конвенциональны и их рассмотрение возможно только в историко-культурном контексте. Так, известный культуролог Г. Гачев рассматривая генезис понятий в разных языках, замечает, что, к примеру, слово «пространство» в латинском языке происходит от слова «шагать», в немецком - от слова «пустота», в русском языке - от слова «страна» [5]. Все это вызывает серьезные трудности при переводе, обуславливает лингвистическую относительность и, как следствие усложняет процессы культурной коммуникации. Необходимо также учитывать факт избыточности языков, специфику их структурной организации и полисемию (практически во всех языках более $80 \%$ слов многозначны). Более того, в каждом языке име- 
ется и так называемая безэквивалентная лексика.

Проблема стала еще более активно обсуждаться после того, как лингвисты Э. Сепир и Б.Л. Уорф [11],[1], и этнологи Ф. Боас и Б. Малиновский [2],[6] пришли к выводу, что культуры и языки народов, находящихся на уровне родоплеменного существования, нельзя рассматривать как примитивные в своем развитии. Они несопоставимы и несоизмеримы с культурными языками современных цивилизаций. Таким образом, диалог между культурами, условно находящимися на разных ступенях развития, может быть существенно затруднен несмотря на возможности перевода с одного языка на другой.

Проблему продолжает рассматривать У. Куйан в своей теории неопределенности перевода. По его мнению, сначала лингвист выдвигает гипотезу о том, что является выражениями согласия и несогласия в туземном языке и находит ее подтверждение в речевом поведении туземцев. Затем он задает туземцам вопросы о предложениях их родного языка при различных стимульных условиях. И так на основе стимульных значений лингвист на первых порах осуществляет перевод некоторых предложений, связанных с наблюдаемой ситуацией. Например, мимо быстро пробегает кролик, туземец говорит «Gavagai», и лингвист-исследователь записывает предложение «Rabbit» (или «Lo, a rabbit») [«Кролик (или «Смотри, кролик»)] в качестве пробного перевода, который далее подвергается проверке в других ситуациях. Поскольку в одном предмете часто совмещаются различные референции (объекты указания различными языковыми выражениями), постольку лингвист бывает вынужден давать даже туземные предложения для одобрения информанта. Так, через фактическое употребление языка и наблюдение поведения туземца на основе большей вероятности одного соответствия языковых выражений двух языков, чем иных других соответствий, лингвист утверждается в своей некоторой рабочей догадке. Если же после выдвижения лингвистом некоторой рабочей гипотезы все его последующие шаги сопровождаются серьезными трудностями, он может отказаться от первоначальной гипотезы и придумать другую [7], [10]. Таким образом, понимание зависит не от уровня развития культуры, а от понимания чужого языка путем отношения к данному лицу, употребляющему язык, через соответствующую реакцию.

Однако, даже относительно точный перевод не всегда способен обеспечить понимания языка и возможности говорить на нем. Даже зная значения слов, сложно понимать какой-либо язык и говорить на нем. Для того чтобы понимать и говорить на языке, необходимо осуществлять множество различных операций, с целью выявить единственно верное значение: конструировать из звуков цепочки слов, из этих цепочек организовывать выражения и конкретное значение и многое другое. При этом осуществляется ряд выборов, правильность которых дает возможность найти соответствие смыслам языковых выражений и контекстуальным особенностям. Не случайно, многие представители неопозитивизма связывали понимание именно со смыслом языковых выражений. Логика рассуждений приводит к необходимости найти дефиницию понятия «смысл».

Наиболее детально с этим понятием попытался разобраться Г. Фреге. Не давая строгого определения смысла, ученый говорит о нем как способе данности объекта, способе указания на объект или информации об объекте. Фреге подчеркивает, что понятие «смысл» имени не должно быть связано с субъективными моментами и ассоциативными характеристиками поскольку они чрезвычайно изменчивы. По мнению автора, «смысл» не следует относить и к психологическим категориям - это абстрактный объект, отличающийся относительной стабильностью.

Смысл соответствует тому, что усваивается носителем языка, когда он понимает имя. Можно всегда понять смысл имени, даже если мы ничего не знаем об объекте, который этим именем обозначен. Например, можно понять имя «точка пересечения а и b» или имя «точка пресечения b и g» и при этом можно не знать, что в треугольнике оба имени обозначают одну и ту же точку [14]. А. Черч также указывает на то, что «смысл» является постулированным абстрактным объектом с определенными постулируемыми свойствами. Однако, на понимание языкового выражения всегда оказывает влияние и субъективная определенность. Таким образом, то, что мы называем «пониманием», имеет две стороны: объективную и субъективную. Объективная сторона заключается в том, что носитель языка постигает значение знака, слова, комплекса знаков. Субъективная сторона заключается в том, что человек при понимании оперирует также определенными собственными ассоциативным образами, опредмечивает свои представления, цели, желания. Притом эти элементы субъективной стороны могут значительно влиять на объективную сторону, ведь люди приписывают знакам своей речи смыслы, которыми эти звуки-знаки сами по себе не обладают. Смыслы образуются тогда, когда человек познавая какие-либо явления окружающей действительности, соотносит их со своими убеждениями, представлениями, ценностями. Эту ситуацию можно выразить и так, что прагматические аспекты использования языка могут модифицировать семантические аспекты. Слова «дом горит» имеют определенный смысл, который мы в состоянии понять, не зная, о каком доме, о каком пожаре и т. п. идет речь. Однако с прагматической точки зрения не безразлично, слышит ли эти слова, произносимые со сцены, человек, находящийся в театральном зрительном зале, или их слышит 
пожарный, находящийся на службе и т. п. [15].

Становление смысла, по справедливому мнению В.П. Волошина, всегда связано со становлением ценностного кругозора человека или определенной социальной группы [4]. Языковые элементы, взятые сами по себе, без отношения к человеку и культуре, никакого смысла не имеют. Чтобы понять особенности языковых аспектов, нужно изучать культуру, в поле которой язык формировался. Языковые знаковые системы выступают как носители смыслов. Можно предположить, что смысл языка не в нем самом, а в культуре, его породившей и он станет понятным тем, кто освоил специфику этой культуры. Одни и те же понятия, языковые выражения в различных культурах и даже в одной и той же культуре в разные эпохи и для разных людей могут иметь различные смыслы. Так, понятие «ответственность» - одно из базовых в гуманитарном знании, поскольку оно включено во все сферы деятельности людей, по-разному трактуется в разных отраслях гуманитарной науки. В правовом знании ответственность определяется как мера государственного принуждения и ее онтологической основой всегда является вина. В психологии ответственность видится как своеобразное состояние сознания, в этике соотносится с понятиями «долг» и «совесть», в социологии трактуется как регулятор социальных взаимодействий. По-разному проявляется ответственность и в разных типах культуры. Для восточных культур характерна невыделенность персональности, коллективистский характер общественных отношений, преобладание религиозных ценностей и речь здесь об ответственности может идти лишь как о следовании эталону, стандарту. В европейской культуре - базовое качество личности - носителя и творца этой культуры. Русская культура не выработала идеала независимой личности-индивидуальности и ответственность чаще всего имеет значение механизма регуляции внешней деятельности и мало связана с внутренним миром человека [13].

Вместе с другими формами освоения мира понимание постигает смысл действительности. Оно выполняет познавательную функцию, объединяя в себе субъективное и объективное, теоретическое и практическое.

Проблему понимания как способ постижения смысла объективного мира через значение языковых выражений пытается решить Л. Витгенштейн. В работе «Философские исследования» он анализирует значение выражений как способ употребления. Значение зависит от контекста употребления слова. Отсюда разнообразие значений языкового знака. Сходство между разными значениями объясняется теорией семейного сходства.

Языку также невозможно навязать единую логику, так как в языке существуют различные правила функциони- рования. Функционирование языка Витгенштейн рассматривает по аналогии с игрой. Употребляя язык, мы участвуем в языковой среде, следуем правилам. Также как и игра, язык - это система действий. Смысл любой игры заключается в ней самой, действия не направлены напрямую на действительность. Поэтому и язык, как система действий, не обладает связью с какой-либо предметной областью. Кроме того, любая игра имеет свои собственные правила, последовательность действий, отличающих ее существенно от других видов игры. Отсюда и значение предложения, как и значение игрового хода, определяется его функцией в игре.

Употребление предложения Витгенштейн сравнивает с шахматным ходом: «...шахматные ходы не являются лишь простым передвижением фигур по доске..., но зависят от условий, которые мы называем «игрой в шахматы», «решением шахматных задач» и тому подобное» [3, с. 33]. Языковой знак можно назвать словом или предложением в том случае, если он является частью человеческой деятельности.

Язык - это сложное образование, которое включает различные типы деятельности с определенными правилами, которые определяют способы употребления слов. Следование правилу определяется, прежде всего, обществом, особенностями жизни. Чтобы понять эти правила необходимо понять весь накопленный опыт их использования.

В §201 «Философских исследований» указывается на то, что понимание правила не связано с интерпретацией, «а обнаруживается в том, что мы называем «следованием правилу» и «действием вопреки» правилу в реальных случаях его применения» [3, с.163]. Таким образом, следование правилу - это общественный опыт. «Чтобы понять, что означает «следование правилу», надо уже уметь следовать ему», считает Витгенштейн. Для этого необходимо обучать навыкам, участвовать в практической деятельности. Все это применяется, согласно его точке зрения, и к изучению языку [8]. «Понять предложение значит, понять язык. Понять язык - значит, овладеть его техникой» [3, с.199] [8]. Научиться пользоваться языком можно только в том случае, если овладеешь формами и видами практики, так как язык является составной частью практики, представляющая собой многообразие [3, c. 65], [8].

Как в «Логико-философском трактате», так и в «Философских исследованиях» Витгенштейн утверждает, что язык обладает способностью на основе своих правил формировать представления о мире [3, с.85].

Кроме того, в теории Л. Витгенштейна отождествляется проблема смысла и проблема правильного употре- 
бления языковых выражений. Такое отождествление не объясняет усвоения конкретным индивидом нового знания с помощью языка, использования одного и того же языка в разных ситуациях и контекстах для выражения разных представлений носителей естественного языка о мире, как происходит понимание смысла действительности, предметного мира [12].

Человек, взаимодействуя с предметами действительности, вовлекает их в свою деятельность. В результате предметы наделяются смыслами в контексте этой дея- тельности. Это и есть процесс возникновения понимания.

В научном познании понимание является результатом языковой коммуникации, которая логически осмысляется. Более того, предполагается соотнесение высказывания действительности, определение истинности или ложности. Поэтому и понимание как компонент познавательной деятельности также подвергается оценке на «истинность - ложность».

\section{ЛИТЕРАТУРА}

1. Американские лингвисты XX века: Сб.обзоров. / Рос. акад. наук. ин-т науч. информ. по обществ. наукам. - М., 2002. - 159 с.

2. Боас, Ф. Ум первобытного человека / Ф. Боас; пер. с англ. А.М. Водена. - М.: URSS: КРАСАНД, 2011. - 153 с.

3. Витгенштейн, Л. Философские исследования / Л. Витгенштейн - М.: АСТ: Астрель, 2011. - 347 с.

4. Волошинов, В.Н. Марксизм и философия языка / В.Н. Волошинов - Л., 1929. - 180 с.

5. Гачев, Г. Национальные образы мира / Г. Гачев. - М., 1995 - 210 с.

6. Гусев, С.С., Тульчинский, Г.Л. Проблема понимания в философии: философско-гносеологический анализ / С.С. Гусев, Г.Л. Тульчинский - М.: Политиздат, 1985. -192 C.

7. Куайн, У.В. Слово и объект / У. В. Куайн. - М.: Праксис: Логос, 2000. - 385 с.

8. Новолодская, Т.А. Диалектическая природа значения языковых выражений (логико-методологические аспекты): дис. ... канд. филос. наук: 09.00 .07 / Новолодская Татьяна Алексеевна - Ленинград, 1983 - 191 с.

9. Рузавин, Г.И. Герменевтика и проблемы понимания и объяснения в научном познании / Г.И. Рузавин // Структура и развитие научного знания. Системный подход к методологии науки. - М.: Мысль, 1981. - С. 10-64

10. Самсонов, В.Ф. Значение и перевод. Спецкурс / В.Ф. Самсонов. - Челябинск, 1978. - 55 с.

11. Сепир, Э. Язык. Введение в изучении речи / Э. Сепир. - Москва; Ленинград: Соцэкгиз, 1934. - 111 с.

12. Терехина, М.И. Гносеологический анализ концепта «значение» в контексте семантики выражений мнения: дис. ... канд. филос. наук: 09.00 .01 / Терехина Майя Ивановна - Магнитогорск, 2004. - 162с.

13. Трофимова, Г.П. Ответственность как категория культуры: дис. ... канд. культурологии: 24.00.01 / Трофимова Галина Петровна - Челябинск 1998.- 164с.

14. Фреге, Г. Смысл и денотат / Г. Фреге // Семиотика и информатика.- М., 1977. - Вып.8.- С. 50- 63

15. Черч, А. Введение в математическую логику / А. Черч - М., 1969. - Т.1. - 484 с. 